\title{
Prevalence and Antibiotic Resistance of Non-typhoidal Salmonella Isolated from Raw Chicken Carcasses of Commercial Broilers and Spent Hens in Tai'an, China
}

\author{
Song $\mathrm{Li}^{1}$, Yufa Zhou ${ }^{2}$ and Zengmin Miao ${ }^{3 *}$ \\ ${ }^{1}$ College of Basic Medicine, Taishan Medical University, Tai'an, China, ${ }^{2}$ Center for Disease Control, Veterinary Bureau of \\ Daiyue, Tai'an, China, ${ }^{3}$ College of Life Sciences, Taishan Medical University, Tai'an, China
}

\section{OPEN ACCESS}

Edited by:

Giovanna Suzzi,

Università di Teramo, Italy

Reviewed by:

Zhao Chen,

University of California, Davis,

United States

Ben Davies Tall,

United States Food and Drug

Administration, United States

*Correspondence:

Zengmin Miao

zengminmiao@126.com

zengminmiao@sina.com

Specialty section: This article was submitted to

Food Microbiology,

a section of the journal

Frontiers in Microbiology

Received: 20 July 2017 Accepted: 16 October 2017 Published: 31 October 2017

Citation:

Li S, Zhou Y and Miao Z (2017) Prevalence and Antibiotic Resistance of Non-typhoidal Salmonella Isolated

from Raw Chicken Carcasses of Commercial Broilers and Spent Hens in Tai'an, China.

Front. Microbiol. 8:2106. doi: 10.3389/fmicb.2017.02106
The present study was aimed to determine the prevalence and characteristics of Salmonella isolated from meat samples of commercial broilers (CB) and spent hens (SH). Between March and June 2016, 200 retail raw chicken carcasses (100 from CB and 100 from SH) were obtained from local supermarkets in Tai'an city of China, and Salmonella isolates were then analyzed for antibiotic resistance, serotype, $\beta$-lactamase genes, and the presence of class 1 integron. Forty Salmonella strains were obtained in this study (CB: 21/100, 21\%; SH: 19/100, 19\%). Three serotypes were identified in 40 Salmonella, and S. Enteritidis (CB: 15/21, 71.4\%; SH: 10/19, 52.6\%) was the dominant serotype, followed by S. Typhimurium (CB: 4/21, 19\%; SH: 6/19, 31.6\%) and S. Derby (CB: 2/21, 9.5\%; SH: 3/19, 15.8\%). Among 21 Salmonella isolated from CB, high antibiotic resistance rates were found for ampicillin (20/21, 95.2\%), nalidixic acid (18/21, 85.7\%), cefotaxime (17/21, 81\%), and tetracycline (13/21, 61.9\%); class 1 integron was observed in seven isolates $(7 / 21,33.3 \%)$, and gene cassettes included an empty integron (0.15 kb, $n=1)$, aadA2 (1.2 kb, $n=3)$, drfA1-aadA1 (1.4 kb, $n=1$ ), and drfA17-aadA5 (1.7 kb, $n=2)$; blaTEM-1 was the dominant $\beta$-lactamase gene (21/21, $100 \%)$, followed by bla high antibiotic resistance rates were found for nalidixic acid (19/19, 100\%), tetracycline (19/19, 100\%), ampicillin (18/19, 94.7\%), and ciprofloxacin (13/19, 68.4\%); class 1 integron was observed in two isolates (2/19, 10.5\%), and gene cassettes included drfA17-aadA5 (1.7 kb, $n=1)$ and drfA1-aadA1 (1.4 kb, $n=1)$; bla TEM-1 was the dominant $\beta$-lactamase gene (19/19, 100\%), followed by bla $\mathrm{CTX}-\mathrm{M}-55$ (2/19, 10.5\%) and bla $\mathrm{CMY}_{-2}(1 / 19,5.3 \%)$. Collectively, antibiotic-resistant Salmonella can be widely detected in retail raw chicken carcasses of $\mathrm{CB}$ and $\mathrm{SH}$, and therefore can pose a serious risk to public health.

Keywords: antibiotic resistance, $\beta$-lactamase gene, class 1 integron, Salmonella, serotype

\section{INTRODUCTION}

Salmonella is a notorious human pathogen and can lead to acute intestinal disease outbreaks in humans through consumption of contaminated foods (Pegues et al., 2006). It has been widely recognized that poultry products, such as eggs and meats, are a crucial transmission vehicle for Salmonella (Kusunoki et al., 2000; Betancor et al., 2010; Painter et al., 2013; Antunes et al., 2016). 
At present and even for a long time in the future, antibioticbased treatment for human salmonellosis infection is the most effective method in clinical practice (Ribeiro et al., 2011; Crump et al., 2015). It is therefore pivotal to use antibiotics to prevent and control Salmonella infections.

However, the widespread use and even abuse of antibiotics in animal husbandry have facilitated the emergence and dissemination of antibiotic resistance in Salmonella, which has posed a serious challenge for the health of animals and humans (Marshall and Levy, 2011; Mukerji et al., 2017). Noticeably, numerous studies in recent years have indicated that extended-spectrum $\beta$-lactamase (ESBL)-producing Salmonella has been frequently isolated from food-producing animals and animal-derived foods in many countries of the world, including China (Wu et al., 2013; Chon et al., 2015; Franco et al., 2015; Hu et al., 2015; Noda et al., 2015; Ziech et al., 2016; Zhao et al., 2017). ESBL-producing Salmonella is able to inactivate and hydrolyze the $\beta$-lactam ring in $\beta$-lactam antibiotics and third- and fourth-generation cephalosporins, leading to the increase of treatment cost and even to therapy failure, which has triggered a serious public concern (Bonnet, 2004; Pitout and Laupland, 2008). In addition, the class 1 integrons are frequently observed among antibioticresistant Salmonella, which contributes to the spread of antibiotic resistance genes among bacteria (Wannaprasat et al., 2011).

Therefore, understanding the prevalence and characteristics of Salmonella isolated from meat samples of food animal origins is of importance for developing effective treatment strategies to control and prevent Salmonella infections in humans and animals. However, information about the occurrence and characteristics of Salmonella in chicken meats in China is poorly documented. In China, two main chicken breeds, including introduced commercial broilers $(\mathrm{CB})$ and spent hens $(\mathrm{SH})$, are widely reared and are important sources of chicken meat (Chen et al., 2016). This study was therefore undertaken to determine the prevalence and characteristics of Salmonella recovered from retail chicken carcasses of $\mathrm{CB}$ and $\mathrm{SH}$ in Tai'an region, China.

\section{MATERIALS AND METHODS}

\section{Sample Collection}

Between March and June 2016, 200 retail raw chicken carcasses without giblets (100 from $\mathrm{CB}$ and 100 from $\mathrm{SH}$ ) were obtained from local supermarkets in Tai'an city, China. These supermarkets had areas of 5,000-10,000 $\mathrm{m}^{2}$, offering various foods and household products, in which raw chicken carcasses were sold refrigerated in a meat department. After purchase, the samples were stored in an icebox and immediately transported into our microbiology laboratory for further processing within $24 \mathrm{~h}$.

\section{Salmonella Isolation and Serotype Identification}

Salmonella isolation was conducted as previously described (Choi et al., 2015). Briefly, each chicken carcass was mixed with $400 \mathrm{ml}$ of buffered peptone water (BPW; Hopebiol,

TABLE 1 | Antibiotic resistance phenotype, presence of class 1 integron, and $\beta$-lactamase genes in Salmonella isolated from CB.

\begin{tabular}{|c|c|c|c|}
\hline Isolates & Serovar & Antibiotic resistance phenotype ${ }^{a}$ & Integron/ $\beta$-lactamase genes \\
\hline $\mathrm{CB}-1$ & S. Derby & AMP, CIP, CTX, NAL, TET & blaTEM-1 \\
\hline CB-12 & S. Enteritidis & AMP, GEN, CTX, FFC, NAL, TET & $($ aadA2)/blatEM-1 \\
\hline CB-14 & S. Enteritidis & AMP, GEN, CTX, FFC, NAL, TET & blatEM-1, bla \\
\hline CB-18 & S. Derby & AMP, CTX, NAL & $(d r f A 1-a a d A 1) / b / a T E M-1$ \\
\hline CB-33 & S. Enteritidis & AMP, GEN, CTX, FFC, NAL, TET & blaTEM-1, bla ${ }_{\mathrm{CTX}}-\mathrm{M}-55$ \\
\hline CB-42 & S. Typhimurium & AMP, GEN, SPT & $($ aadA2)/bla TEM-1 \\
\hline CB-48 & S. Typhimurium & AMP, SPT & blaTEM-1 \\
\hline CB-49 & S. Enteritidis & AMP, GEN, CTX, FFC, NAL, TET & blateM-1, bla $a_{\mathrm{CTX}-\mathrm{M}-55}$ \\
\hline CB-51 & S. Enteritidis & AMP, CTX, NAL & blaTEM-1 \\
\hline CB-58 & S. Enteritidis & AMP, GEN, CTX, FFC, NAL, TET & blaTEM-1 \\
\hline CB-59 & S. Enteritidis & AMP, CTX, FFC, NAL, TET & blateM-1, blacTX-M-55 \\
\hline CB-63 & S. Enteritidis & AMP, GEN, CTX, FFC, NAL, TET & $(d r f A 17-a a d A 5) / b / a T_{E M}-1, b / a_{\mathrm{CTX}}-\mathrm{M}-55$ \\
\hline CB-65 & S. Enteritidis & AMP, GEN, CTX, FFC, NAL, TET & bla TEM-1 \\
\hline CB-71 & S. Enteritidis & AMP, GEN, CTX, FFC, NAL, TET & $(d r f A 17-a a d A 5) / b / a$ TEM-1 \\
\hline CB-79 & S. Enteritidis & AMP, GEN, CTX, FFC, NAL, TET & bla TEM -1, bla \\
\hline CB-81 & S. Typhimurium & AMP, SPT & $(\mathrm{aadA2}) / \mathrm{blaTEM}-1$ \\
\hline CB-88 & S. Enteritidis & $\mathrm{NAL}$ & blaTEM-1 \\
\hline CB-89 & S. Enteritidis & AMP, GEN, CTX, FFC, NAL, TET & blaTEM-1, bla ${ }_{\mathrm{CTX}-\mathrm{M}-55}$ \\
\hline CB-91 & S. Enteritidis & AMP, CIP, CTX, NAL, TET & blaTEM-1 \\
\hline CB-96 & S. Enteritidis & AMP, CTX, NAL & empty integron/blaTEM-1 \\
\hline CB-98 & S. Typhimurium & AMP, CTX, NAL & blaTEM-1 \\
\hline
\end{tabular}

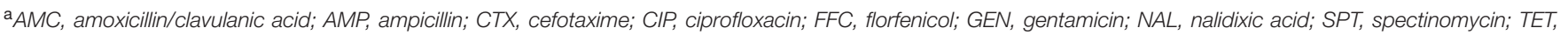
tetracycline; SXT, sulfamethoxazole/trimethoprim. 
TABLE 2 | Antibiotic resistance phenotype, presence of class 1 integron, and $\beta$-lactamase genes in Salmonella isolated from $\mathrm{SH}$.

\begin{tabular}{|c|c|c|c|}
\hline Isolates & Serovar & $\begin{array}{l}\text { Antibiotic } \\
\text { resistance } \\
\text { phenotype }^{b}\end{array}$ & $\begin{array}{l}\text { Integron/ } \\
\beta \text {-lactamase } \\
\text { genes }\end{array}$ \\
\hline $\mathrm{SH}-3$ & S. Enteritidis & NAL & blaTEM-1 \\
\hline $\mathrm{SH}-5$ & S. Enteritidis & AMP, NAL, TET & bla TEM-1 \\
\hline $\mathrm{SH}-8$ & S. Enteritidis & $\begin{array}{l}\text { AMP, CTX, CIP, } \\
\text { NAL, TET }\end{array}$ & $\begin{array}{l}\text { blaTEM-1, } \\
\text { bla }\end{array}$ \\
\hline $\mathrm{SH}-13$ & S. Derby & AMP, CIP, NAL, TET & blaTEM-1 \\
\hline $\mathrm{SH}-21$ & S. Enteritidis & AMP, NAL, TET & blaTEM-1 \\
\hline $\mathrm{SH}-26$ & S. Enteritidis & AMP, NAL, TET & bla TEM-1 \\
\hline $\mathrm{SH}-33$ & S. Enteritidis & AMP, CIP, NAL, TET & bla TEM-1 \\
\hline $\mathrm{SH}-35$ & S. Enteritidis & $\begin{array}{l}\text { AMP, CIP, CTX, } \\
\text { NAL, TET }\end{array}$ & $\begin{array}{l}(\text { drfA17- } \\
\text { aadA5)/bla TEM-1 }\end{array}$ \\
\hline $\mathrm{SH}-48$ & S. Enteritidis & AMP, CIP, NAL, TET & blaTEM-1 \\
\hline $\mathrm{SH}-50$ & S. Enteritidis & AMP, CIP, NAL, TET & blaTEM-1 \\
\hline SH53 & S. Derby & AMP, NAL, TET & blaTEM-1 \\
\hline $\mathrm{SH}-61$ & S. Typhimurium & $\begin{array}{l}\text { AMP, CTX, CIP, } \\
\text { NAL, TET }\end{array}$ & $\begin{array}{l}\text { blaTEM-1, } \\
\text { bla }_{\text {CTX-M-55 }}\end{array}$ \\
\hline SH-66 & S. Typhimurium & AMP, CIP, NAL, TET & blaTEM-1 \\
\hline $\mathrm{SH}-73$ & S. Typhimurium & AMP, NAL, TET & blaTEM-1 \\
\hline $\mathrm{SH}-75$ & S. Typhimurium & AMP, CIP, NAL, TET & blaTEM-1 \\
\hline $\mathrm{SH}-88$ & S. Typhimurium & $\begin{array}{l}\text { AMP, CIP, CTX, } \\
\text { GEN, NAL, TET }\end{array}$ & $\begin{array}{l}(\text { drfA 1- } \\
\text { aadA1)/bla TEM-1, } \\
\text { bla } \mathrm{CMY-2}\end{array}$ \\
\hline $\mathrm{SH}-90$ & S. Typhimurium & AMP, CIP, NAL, TET & blaTEM-1 \\
\hline $\mathrm{SH}-93$ & S. Enteritidis & AMP, CIP, NAL, TET & blaTEM-1 \\
\hline SH-96 & S. Derby & AMP, CIP, NAL, TET & blaTEM-1 \\
\hline
\end{tabular}

bAMC, amoxicillin/clavulanic acid; AMP, ampicillin; CTX, cefotaxime; CIP, ciprofloxacin; FFC, florfenicol; GEN, gentamicin; NAL, nalidixic acid; SPT, spectinomycin; TET, tetracycline; and SXT, sulfamethoxazole/trimethoprim.

Qingdao, China) contained in a sterile plastic bag to rinse for $1 \mathrm{~min}$ by gentle shaking. Twenty-five milliliter of the rinsate was mixed with $25 \mathrm{~mL}$ of $2 \times \mathrm{BPW}$ and the mixture was incubated overnight at $37^{\circ} \mathrm{C}$. A $100 \mu \mathrm{L}$ aliquot was removed form the BPW enrichment broth and inoculated into Rappaport-Vassiliadis soy peptone broth $(10 \mathrm{~mL})$ (RVS; Hopebiol, Qingdao, China), which was incubated for $24 \mathrm{~h}$ at $42^{\circ} \mathrm{C}$. One loopful of the RVS culture was streaked onto a xylose lysine desoxycholate agar plate (XLD; Hopebiol, Qingdao, China), which was incubated overnight at $37^{\circ} \mathrm{C}$. The suspected Salmonella colony (red colonies with black centers) on the XLD plates from each chicken meat sample was identified by biochemical confirmation using biochemical tubes (Hopebiol, Qingdao, China), and the results were interpreted according to Bergey's Manual of Systematic Bacteriology (Garrity et al., 2004).

According to the Kauffmann-White scheme, slide agglutination tests were used to serotype Salmonella isolates in this study (S\&A Reagents Lab, Bangkok, Thailand).

\section{Antimicrobial Susceptibility Testing}

Based on the guidelines of the Clinical and Laboratory Standards Institute (Clinical and Laboratory Standards Institute [CLSI], 2013), the disk diffusion method was employed to determine antibiotic susceptibilities of Salmonella strains. Antibiotics used in this study were amoxicillin/clavulanic acid $(20 / 10 \mu \mathrm{g})$, ampicillin $(10 \mu \mathrm{g})$, cefotaxime $(30 \mu \mathrm{g})$, ciprofloxacin (5 $\mu \mathrm{g}$ ), florfenicol (30 $\mu \mathrm{g})$, gentamicin (10 $\mu \mathrm{g}$ ), nalidixic acid $(10 \mu \mathrm{g})$, spectinomycin $(10 \mu \mathrm{g})$, tetracycline $(30 \mu \mathrm{g})$ and sulfamethoxazole/trimethoprim (1.25/23.75 $\mu \mathrm{g}$ ) (Hopebiol, Qingdao, China). Salmonella strains resistant to no less than three classes of antibiotics were defined as multidrug-resistant (MDR) isolates. Escherichia coli ATCC 25922 was used in this study as quality control strain.

\section{Detection of $\beta$-Lactamase Gene}

According to the method previously described (Batchelor et al., 2005; Rayamajhi et al., 2008; Li et al., 2013), polymerase chain reaction (PCR) was used to determine the presence of $\beta$-lactamase genes (bla $a_{\mathrm{TEM}}, b l a_{\mathrm{PSE}-1}, b l a_{\mathrm{CMY}-2}, b l a_{\mathrm{SHV}}$, $b l a_{\mathrm{DHA}-1}, b l a_{\mathrm{OXA}}$, and $\left.b l a_{\mathrm{CTX}-\mathrm{M}}\right)$. For isolates carrying $b l a_{\mathrm{CTX}-\mathrm{M}}$ genes, $b l a_{\mathrm{CTX}-\mathrm{M}}$ gene group was further identified by using PCR (Kim et al., 2015). The PCR products were sequenced (Sunny, Shanghai, China), and the sequences were analyzed and aligned using the NCBI BLAST program ${ }^{1}$.

\section{Detection of Class I Integrons}

Based on the primers previously described, PCR was used to analyze the presence of class 1 integron (Guerra et al., 2001; Kerrn et al., 2002). Additionally, PCR was employed to amplify gene cassettes within the variable region of class 1 integron according to the methods described previously (Sandvang et al., 1998). The amplification fragments were cloned into the pMD18T vector (Takara, Dalian, China), which were sequenced (Sunny, Shanghai, China).

\section{Statistical Analyses}

Fisher's exact test was used to compare the prevalence of Salmonella and proportions of class 1 integron in Salmonella in CB and SH using SPSS 16.0 software (IBM, United States). $P$-values of less than 0.05 were defined as difference significance.

\section{RESULTS}

\section{Salmonella Prevalence}

A total of 40 Salmonella strains (40/200, 20\%) were isolated from the foods, and the prevalence in CB was $21 \%(21 / 100)$ and $19 \%$ $(19 / 100)$ in SH. No significant difference was found in Salmonella prevalence between $\mathrm{CB}$ and $\mathrm{SH}$ samples $(P>0.05)$.

\section{Serotyping and Antimicrobial \\ Susceptibility Testing}

Three serotypes were identified in 40 Salmonella strains. S. Enteritidis (CB: 15/21, 71.4\%; SH: 10/19, 52.6\%) was the dominant serotype, followed by S. Typhimurium (CB: 4/21, 19\%; SH: 6/19, 31.6\%) and S. Derby (CB: $2 / 21,9.5 \%$; SH: 3/19, 15.8\%) (Tables 1, 2).

\footnotetext{
${ }^{1}$ http://www.ncbi.nlm.nih.gov/BLAST
} 


\section{Prevalence of Class 1 Integron and $\beta$-Lactamase Genes}

Among 21 Salmonella isolated from CB, class 1 integron was observed in seven isolates $(7 / 21,33.3 \%)$, and gene cassettes included an empty integron $(0.15 \mathrm{~kb}, n=1)$, aadA2 $(1.2 \mathrm{~kb}$, $n=3), \operatorname{drfA1}$-aadA1 $(1.4 \mathrm{~kb}, n=1)$, and drfA17-aadA5 $(1.7 \mathrm{~kb}$, $n=2)$; bla $a_{\mathrm{TEM}-1}$ was the dominant $\beta$-lactamase gene $(21 / 21$, $100 \%)$, followed by bla $_{\mathrm{CTX}-\mathrm{M}-55}(7 / 21,33.3 \%)$ (Table 1). Among 19 Salmonella isolated from SH, class 1 integron was observed in two isolates $(2 / 19,10.5 \%)$, and gene cassettes included $d r f A 17$ aadA5 $(1.7 \mathrm{~kb}, n=1)$ and drfA1-aadA1 $(1.4 \mathrm{~kb}, n=1)$; bla TEM -1 was the dominant $\beta$-lactamase gene $(19 / 19,100 \%)$, followed by bla $_{\mathrm{CTX}-\mathrm{M}-55}(2 / 19,10.5 \%)$ and bla $_{\mathrm{CMY}-2}(1 / 19,5.3 \%)$ (Table 2). Of note, the proportion of class 1 integron targets detected in Salmonella strains from CB samples was higher than that found in SH samples (33.3\% vs. $10.5 \%, P<0.05)$.

\section{DISCUSSION}

In the present study, $20 \%$ of 200 retail chicken carcasses were Salmonella positive. The prevalence of Salmonella in poultry meat products in other parts of China has been reported by others to be approximately $36.1 \%$ (Cui H.X. et al., 2009) and $28.3 \%$ (Li et al., 2013). The prevalence in other regions of the world was $15.6 \%$ in chicken carcasses in EU (European Food Safety Authority [EFSA], 2010) and $45.8 \%$ in retail chicken meat in Korea (Park et al., 2017). These investigations indicated that Salmonella contamination is widely distributed in poultry meats. Of note, it is difficult to compare the prevalence of Salmonella among different studies, because the difference may be associated with geographical differences, sampling seasons, sample types, methodology of isolation and culture, and environments of slaughterhouses and marketing areas (Yan et al., 2010; Yang et al., 2010).

Salmonella Enteritidis was the most commonly isolated serotype in this study, and has been widely isolated in chickens, eggs, and chicken meats in China (Yang et al., 2010; Lu et al., 2011; Long et al., 2016). In addition, S. Enteritidis is the leading cause of Salmonella related food-borne outbreaks in humans worldwide (Galanis et al., 2006). Of note, S. Typhimurium is the main serotype isolated from humans in China (Deng et al., 2012) and $S$. Derby is the most common serotype isolated from infants and toddlers in China (Cui S. et al., 2009), which suggested that an association may exist between Salmonella-contaminated food and salmonellosis in these age groups.

Similar antibiotic resistance patterns were observed in Salmonella isolated from $\mathrm{CB}$ and $\mathrm{SH}$. Of 21 Salmonella isolated from $\mathrm{CB}$, high antibiotic resistance rates were found

\section{REFERENCES}

Antunes, P., Mourão, J., Campos, J., and Peixe, L. (2016). Salmonellosis: the role of poultry meat. Clin. Microbiol. Infect. 2, 110-121. doi: 10.1016/j.cmi.2015.12.004 Batchelor, M., Hopkins, K., Threlfall, E. J., Clifton-Hadley, F. A., Stallwood, A. D., Davies, R. H., et al. (2005). bla (CTX-M) genes in clinical Salmonella isolates for ampicillin (20/21, 95.2\%), nalidixic acid (18/21, 85.7\%), cefotaxime (17/21,81\%), and tetracycline $(13 / 21,61.9 \%)$; and 18 out of 21 Salmonella were MDR isolates (85.7\%). Among 19 Salmonella isolated from $\mathrm{SH}$, high antibiotic resistance rates were found for nalidixic acid (19/19, 100\%), tetracycline (19/19, 100\%), ampicillin (18/19, 94.7\%), and ciprofloxacin (13/19, 68.4\%); and 17 of 19 Salmonella were MDR strains (89.5\%). No significant difference $(P>0.05)$ in the prevalence of MDR Salmonella between $\mathrm{CB}$ and $\mathrm{SH}$. Of note, co-resistance to ciprofloxacin and cefotaxime in these Salmonella strains would limit therapeutic options in clinical practice (Whichard et al., 2007).

All class 1 integron-positive isolates in this study exhibited resistance to at least two classes of antibiotics, which supports the hypothesis that there is a strong association between the presence of class I integron and the emerging of MDR in Salmonella (Wannaprasat et al., 2011; Firoozeh et al., 2012).

All Salmonella isolates in this study carried $b a_{\mathrm{TEM}-1}$ genes, 38 of which showed were resistant to ampicillin. Noticeably, one

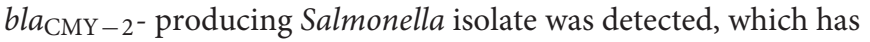
been observed in chicken meat in 2010-2011 in Sichuan province of China (Li et al., 2013). Because bla $a_{\mathrm{CMY}-2}$ can encode antibiotic resistance to third-generation cephalosporins, which is frequently used to treat cases of salmonellosis (Gonzalez-Sanz et al., 2009),

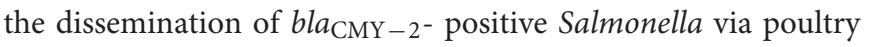
meat products has pivotal public health implications. Therefore, the poultry industry should follow prudent management by establishing more effective disinfection guidelines to reduce the population of antibiotic-resistant pathogens. Moreover, a moderate use of antibiotics may help prevent the occurrence of antibiotic resistance in pathogens (Chen and Jiang, 2014).

\section{CONCLUSION}

To our best knowledge, this is the first study in China comparing the prevalence and characteristics of Salmonella isolated from chicken meat samples of CB and SH. Regardless of chicken meat type, 25\% (10/40) of the Salmonella isolates in this study carried ESBL-producing genes; $22.5 \%$ (9/40) of the Salmonella isolates contained class 1 integrons. Therefore, the reasonable use of antibiotics in animal husbandry should be taken, and continued long-term surveillance of Salmonella in animal-derived foods is warranted.

\section{AUTHOR CONTRIBUTIONS}

ZM designed the study; SL and YZ collected samples and conducted the experiments; ZM, SL, and YZ analyzed data and wrote the manuscript.

recovered from humans in England and Wales from 1992 to 2003. Antimicrob. Agents Chemother. 49, 1319-1322. doi: 10.1128/AAC.49.4.1319-1322.2005

Betancor, L., Pereira, M., Martinez, A., Giossa, G., Fookes, M., Flores, K., et al. (2010). Prevalence of Salmonella enterica in poultry and eggs in Uruguay during an epidemic due to Salmonella enterica serovar Enteritidis. J. Clin. Microbiol. 48, 2413-2423. doi: 10.1128/JCM.02137-09 
Bonnet, R. (2004). Growing group of extended-spectrum $\beta$-lactamases: the CTXM enzymes. Antimicrob. Agents Chemother. 48, 1-14. doi: 10.1128/AAC.48.1.114.2004

Chen, Y., Qiao, Y., Xiao, Y., Chen, H., Zhao, L., Huang, M., et al. (2016). Differences in physicochemical and nutritional properties of breast and thigh meat from crossbred chickens, commercial broilers, and spent hens. Asian Australas. J. Anim. Sci. 29, 855-864. doi: 10.5713/ajas.15.0840

Chen, Z., and Jiang, X. (2014). Microbiological safety of chicken litter or chicken litter-based organic fertilizers: a review. Agriculture 4, 1-29. doi: 10.3390/ agriculture 4010001

Choi, D., Chon, J. W., Kim, H. S., Kim, D. H., Lim, J. S., Yim, J. H., et al. (2015). Incidence, antimicrobial resistance, and molecular characteristics of nontyphoidal Salmonella including extended-spectrum $\beta$-lactamase producers in retail chicken meat. J. Food Prot. 78, 1932-1937. doi: 10.4315/0362-028X. JFP-15-145

Chon, J. W., Jung, H. I., Kuk, M., Kim, Y. J., Seo, K. H., and Kim, S. K. (2015). High occurrence of extended-spectrum $\beta$-lactamase-producing Salmonella in broiler carcasses from poultry slaughterhouses in South Korea. Foodborne Pathog. Dis. 12, 190-196. doi: 10.1089/fpd.2014.1847

Clinical and Laboratory Standards Institute [CLSI] (2013). Performance Standards for Antimicrobial Susceptibility Testing, 23rd Informational Supplement M100S23. Wayne, PA: Clinical and Laboratory Standards Institute.

Crump, J. A., Sjölund-Karlsson, M., Gordon, M. A., and Parry, C. M. (2015). Epidemiology, clinical presentation, laboratory diagnosis, antimicrobial resistance, and antimicrobial management of invasive Salmonella infections. Clin. Microbiol. Rev. 28, 901-937. doi: 10.1128/CMR.00002-15

Cui, H. X., Zhang, X. L., Liao, X. G., Zhang, D., Hu, D., Zhang, M., et al. (2009). Monitoring and analysis for food-borne pathogens in Henan in 2007. Chin. J. Health Lab Technol. 19, 173-175.

Cui, S., Li, J., Sun, Z., Hu, C., Jin, S., Li, F., et al. (2009). Characterization of Salmonella enterica isolates from infants and toddlers in Wuhan, China. J. Antimicrob. Chemother. 63, 87-94. doi: 10.1093/jac/dkn452

Deng, X., Ran, L., Wu, S., Ke, B., He, D., Yang, X., et al. (2012). Laboratory-based surveillance of non-typhoidal Salmonella infections in Guangdong Province, China. Foodborne Pathog. Dis. 9, 305-312. doi: 10.1089/fpd.2011.1008

European Food Safety Authority [EFSA] (2010). Analysis of the baseline survey on the prevalence of Campylobacter in broiler batches and of Campylobacter and Salmonella on broiler carcasses in the EU, 2008, part A: Campylobacter and Salmonella prevalence estimates. EFSA J. 8, 1503.

Firoozeh, F., Zahraei-Salehi, T., Shahcheraghi, F., Karimi, V., and Aslani, M. M. (2012). Characterization of class I integrons among Salmonella enterica serovar Enteritidis isolated from humans and poultry. FEMS Immunol. Med. Microbiol. 64, 237-243. doi: 10.1111/j.1574-695X.2011.00883.x

Franco, A., Leekitcharoenphon, P., Feltrin, F., Alba, P., Cordaro, G., Iurescia, M., et al. (2015). Emergence of a clonal lineage of multidrug-resistant ESBLproducing Salmonella Infantis transmitted from broilers and broiler meat to humans in Italy between 2011 and 2014. PLOS ONE 10:e0144802. doi: 10.1371/ journal.pone.0144802

Galanis, E., Lo Fo Wong, D. M., Patrick, M. E., Binsztein, N., Cieslik, A., Chalermchikit, T., et al. (2006). Web-based surveillance and global Salmonella distribution, 2000-2002. Emerg. Infect. Dis. 12, 381-388. doi: 10.3201/eid1205. 050854

Garrity, G. M., Bell, J. A., and Lilburn, T. G. (2004). Bergey's Manual of Systematic Bacteriology, 2nd Edn. New York, NY: Springer.

Gonzalez-Sanz, R., Herrera-Leon, S., de la Fuente, M., Arroyo, M., and Echeita, M. A. (2009). Emergence of extended-spectrum beta-lactamases and AmpCtype beta-lactamases in human Salmonella isolated in Spain from 2001 to 2005. J. Antimicrob. Chemother. 64, 1181-1186. doi: 10.1093/jac/dkp361

Guerra, B., Soto, S. M., Arguelles, J. M., and Mendoza, M. C. (2001). Multidrug resistance is mediated by large plasmids carrying a class 1 integron in the emergent Salmonella enterica serotype [4,5,12:i:-]. Antimicrob. Agents Chemother. 45, 1305-1308. doi: 10.1128/AAC.45.4.1305-1308.2001

Hu, Y. J., Wang, Y. R., and Li, F. Q. (2015). Study on simultaneous contamination of Salmonella and Campylobacter in retail chicken carcasses in Beijing. J. Hyg. Res. 44, 68-72.

Kerrn, M. B., Klemmensen, T., Frimodt-Moller, N., and Espersen, F. (2002). Susceptibility of Danish Escherichia coli strains isolated from urinary tract infections and bacteraemia, and distribution of sul genes conferring sulphonamide resistance. J. Antimicrob. Chemother. 50, 513-516. doi: 10.1093/ jac/dkf164

Kim, H. S., Chon, J. W., Kim, Y. J., Kim, D. H., Kim, M. S., and Seo, K. H. (2015). Prevalence and characterization of extended-spectrum- $\beta$-lactamase-producing Escherichia coli and Klebsiella pneumoniae in ready-to-eat vegetables. Int. J. Food Microbiol. 207, 83-86. doi: 10.1016/j.ijfoodmicro.2015.04.049

Kusunoki, K., Jin, M., Iwaya, M., Ishikami, T., Kurimoto, K., Saito, K., et al. (2000). Salmonella contamination in domestic raw chickens in Tama, Tokyo, and serovar or drug-resistance of isolates (1992-1999). Jpn. J. Food Microbiol. 17, 207-212. doi: 10.5803/jsfm.17.207

Li, R., Lai, J., Wang, Y., Liu, S., Li, Y., Liu, K., et al. (2013). Prevalence and characterization of Salmonella species isolated from pigs, ducks and chickens in Sichuan Province, China. Int. J. Food Microbiol. 163, 14-18. doi: 10.1016/j. ijfoodmicro.2013.01.020

Long, M., Lai, H., Deng, W., Zhou, K., Li, B., Liu, S., et al. (2016). Disinfectant susceptibility of different Salmonella serotypes isolated from chicken and egg production chains. J. Appl. Microbiol. 121, 672-681. doi: 10.1111/jam.13184

Lu, Y., Wu, C. M., Wu, G. J., Zhao, H. Y., He, T., Cao, X. Y., et al. (2011). Prevalence of antimicrobial resistance among Salmonella isolates from chicken in china. Foodborne Pathog. Dis. 8, 45-53. doi: 10.1089/fpd.2010.0605

Marshall, B. M., and Levy, S. B. (2011). Food animals and antimicrobials: impacts on human health. Clin. Microbiol. Rev. 24, 718-733. doi: 10.1128/CMR.00 002-11

Mukerji, S., O’Dea, M., Barton, M., Kirkwood, R., Lee, T., and Abraham, S. (2017). Development and transmission of antimicrobial resistance among Gramnegative bacteria in animals and their public health impact. Essays Biochem. 61, 23-35. doi: 10.1042/EBC20160055

Noda, T., Murakami, K., Etoh, Y., Okamoto, F., Yatsuyanagi, J., Sera, N., et al. (2015). Increase in resistance to extended-spectrum cephalosporins in Salmonella isolated from retail chicken products in Japan. PLOS ONE 10:e0116927. doi: 10.1371/journal.pone.0116927

Painter, J. A., Hoekstra, R. M., Ayers, T., Tauxe, R. V., Braden, C. R., Angulo, F. J., et al. (2013). Attribution of food-borne illnesses, hospitalizations, and deaths to food commodities by using outbreak data, United States, 1998-2008. Emerg. Infect. Dis. 19, 407. doi: 10.3201/eid1903.111866

Park, J. H., Kim, H. S., Yim, J. H., Kim, Y. J., Kim, D. H., Chon, J. W., et al. (2017). Comparison of the isolation rates and characteristics of Salmonella isolated from antibiotic-free and conventional chicken meat samples. Poult. Sci. doi: $10.3382 /$ ps/pex055 [Epub ahead of print].

Pegues, D. A., Ohl, M. E., and Miller, S. I. (2006). Nontyphoidal salmonellosis. Trop. Infect. Dis. 1, 241-254.

Pitout, J. D., and Laupland, K. B. (2008). Extended-spectrum $\beta$-lactamaseproducing Enterobacteriaceae: an emerging public health concern. Lancet Infect. Dis. 8, 159-166. doi: 10.1016/S1473-3099(08)70041-0

Rayamajhi, N., Kang, S. G., Lee, D. Y., Kang, M. L., Lee, S. I., Park, K. Y., et al. (2008). Characterization of TEM-, SHV- and AmpC-type beta-lactamases from cephalosporin-resistant Enterobacteriaceae isolated from swine. Int. J. Food Microbiol. 124, 183-187. doi: 10.1016/j.ijfoodmicro.2008.03.009

Ribeiro, V. B., Lincopan, N., Landgraf, M., Franco, B. D., and Destro, M. T. (2011). Characterization of class I integrons and antibiotic resistance genes in multidrug-resistant Salmonella enterica isolates from foodstuff and related sources. Braz. J. Microbiol. 42, 685-692. doi: 10.1590/S1517838220110002000033

Sandvang, D., Aarestrup, F. M., and Jensen, L. B. (1998). Characterization of integrons and antibiotic resistance genes in Danish multiresistant Salmonella enterica Typhimurium DT104. FEMS Microbiol. Lett. 160, 37-41. doi: 10.1111/ j.1574-6968.1998.tb12887.x

Wannaprasat, W., Padungtod, P., and Chuanchuen, R. (2011). Class 1 integrons and virulence genes in Salmonella enterica isolates from pork and humans. Int. J. Antimicrob. Agents 37, 457-461. doi: 10.1016/j.ijantimicag.2010.12.001

Whichard, J. M., Gay, K., Stevenson, J. E., Joyce, K. J., Cooper, K. L., Omondi, M., et al. (2007). Human Salmonella and concurrent decreased susceptibility to quinolones and extended-spectrum cephalosporins. Emerg. Infect. Dis. 13, 1681-1688. doi: 10.3201/eid1311.061438

Wu, H., Xia, X., Cui, Y., Hu, Y., Xi, M., Wang, X., et al. (2013). Prevalence of extended-spectrum $\beta$-lactamase-producing Salmonella on retail chicken in six provinces and two national cities in the People's Republic of China. J. Food Prot. 76, 2040-2044. doi: 10.4315/0362-028X.JFP-13-224 
Yan, H., Li, L., Alam, M. J., Shinoda, S., Miyoshi, S., and Shi, L. (2010). Prevalence and antimicrobial resistance of Salmonella in retail foods in northern China. Int. J. Food Microbiol. 143, 230-234. doi: 10.1016/j.ijfoodmicro.2010.07.034

Yang, B., Qu, D., Zhang, X., Shen, J., Cui, S., Shi, Y., et al. (2010). Prevalence and characterization of Salmonella serovars in retail meats of marketplace in Shaanxi, China. Int. J. Food Microbiol. 141, 63-72. doi: 10.1016/j.ijfoodmicro. 2010.04.015

Zhao, X., Ye, C., Chang, W., and Sun, S. (2017). Serotype distribution, antimicrobial resistance, and class 1 integrons profiles of Salmonella from animals in slaughterhouses in Shandong province, China. Front. Microbiol. 8:1049. doi: 10.3389/fmicb.2017.01049

Ziech, R. E., Lampugnani, C., Perin, A. P., Sereno, M. J., Sfaciotte, R. A., Viana, C., et al. (2016). Multidrug resistance and ESBL-producing Salmonella spp. isolated from broiler processing plants. Braz. J. Microbiol. 47, 191-195. doi: 10.1016/j. bjm.2015.11.021

Conflict of Interest Statement: The authors declare that the research was conducted in the absence of any commercial or financial relationships that could be construed as a potential conflict of interest.

Copyright (C) $2017 \mathrm{Li}$, Zhou and Miao. This is an open-access article distributed under the terms of the Creative Commons Attribution License (CC BY). The use, distribution or reproduction in other forums is permitted, provided the original author(s) or licensor are credited and that the original publication in this journal is cited, in accordance with accepted academic practice. No use, distribution or reproduction is permitted which does not comply with these terms. 